\title{
Learning management systems with emphasis on the Moodle at UniSA
}

\author{
Anusua Ghosh ${ }^{\mathrm{a}, 1, *}$, Andrew Nafalski ${ }^{\mathrm{a}, 2}$, Zorica Nedic ${ }^{\mathrm{a}, 3}$, Aji Prasetya Wibawa ${ }^{\mathrm{b}, 4}$ \\ ${ }^{a}$ University of South Australia, Adelaide, Australia \\ ${ }^{\mathrm{b}}$ Department of Electrical Engineering, Universitas Negeri Malang, Indonesia \\ ' anusua.ghosh@mymail.unisa.edu.au*; ${ }^{2}$ andrew.nafalski@unisa.edu.au; ${ }^{3}$ zorica.nedic@unisa.edu.au; ${ }^{4}$ aji.prasetya.ft@um.ac.id \\ * corresponding author
}

ARTICLE INFO ABSTRACT

Article history

Received December 23, 2018

Revised January 20, 2019

Accepted February 7, 2019

Keywords

Learning management system

E-learning

Moodle

UniSA Netlab
With recent advances in technology and the Internet, the concept of teaching and learning have evolved significantly. Conventional face-to-face teaching is becoming a thing of the past as knowledge is everywhere and accessible from anywhere. Thus, a shift to e-learning is gaining momentum. Educational institute, companies, individuals and training organizations are embracing new technology and creating a shared online platform to facilitate learning, referred to as the Learning Management Systems (LMS). LMS are software that provide an online portal to collaborate in teaching and learning seamlessly, making it more productive and engaging. This paper aims to review the top ten LMSs both cloud based and open source with regards to their compatibility, usefulness, security, accessibility, scalability, stability/reliability and de-sign in general with emphasis on the recent development of the Moodle and NetLab at University of South Australia (UniSA). The open source online learning platform Moodle is adopted by UniSA to provide educators a space for collaborative learning using the optimized tools to create activities. Moreover, the Netlab online remote laboratory developed at UniSA, provides a platform for academic staff for teaching and demonstrations during lectures and for students to conduct practical experiments remotely on real laboratory equipment.

This is an open access article under the CC-BY-SA license.

\section{Introduction}

The Internet has revolutionized the way knowledge is deployed and acquired. Conventional faceto-face teaching is becoming a thing of the past as knowledge is everywhere and accessible from anywhere. E-learning is gaining momentum as it enables user to access information over the Internet outside their conventional area; the classroom. As individual responds to learning differently, elearning provides the platform that facilitates various needs and options to cater for learners to learn efficiently. Therefore, in comparison to traditional face-to-face learning it is more convenient and easier to access online resources which would normally be di cult or unavailable. Universities and training organization are now embracing the technology and imparting teaching and learning effectively using online platform. With technology reshaping our education system, and increase in online learning, a system to manage the online program arose. These online management systems are known as Learning Management System (LMS). LMS are software that provide an online portal to collaborate teaching and learning seamlessly, making it more productive and engaging. Moreover, LMS provide the space for educators and learners to collaborate in a way that is progressive and $\mathrm{e}$ effective. Moreover, LMS empowers e-learning as it provides the basic tools to organize, deliver and manage online educational courses using a single portal. This paper is organized as follows: Section II presents an overview of the learning management systems including critical review with regards to their compatibility, usefulness, security, accessibility, scalability, stability/reliability and design. In Section III the recent development of the Moodle at UniSA will be outlined. The 
development of the online remote laboratory Netlab at UniSA is followed in Section IV. Finally, Section V concludes the work.

\section{Learning Management Systems}

Smart technology, internet access, and e-learning are leveraging users to explore, gain and deliver knowledge in a streamlined and productive way. Virtual learning environments and networked learning will increasingly become key factors in the delivery of training and education in the $21 \mathrm{~s}$ century [1].Today universities/training organizations are offering online courses/training so that user can remotely access course content and collaborate; aiming to develop a con-textual collaborative space within the teaching and learning environment. This knowledge sharing requires a robust platform to benchmark and manage online content. The amalgamation of online and traditional practice are also referred to as blended learning and has been suggested by many researcher to be effective in facilitating the process of online collaborative learning [2]-[7].

\subsection{Overview of LMS}

Learning Management System (LMS) as shown in Fig.1 are an online platform developed to facilitate collaborative teaching and learning. Blended learning defined above is supported extensively by learning management system (LMS) or Course management system (CMS) used interchangeably [8]. Gagne et. al. define a CMS as a system that provides the tools for the development and delivery of courses, which are placed onto the Internet, whereas they de ne a LMS as a management system delivering online learning [9]. Hall defines an LMS as "Software that provides the platform for the enterprise's online learning environment by enabling the management, delivery and tracking of blended learning (online and traditional classroom) for employees, stakeholders and customers" [10].

LMSs and online learning platforms available for both K-12 and higher education [11]. A robust LMS should integrate with other departments, such as human resources, accounting and ecommerce, so administrative and supervisory tasks can be streamlined and automated and the overall cost and impact of education can be tracked and quantified. He also pointed out that an $\backslash$ LMS should support a collaborative learning community, offering multiple modes of learning from self-paced coursework (Web-based seminars and classes, down-loadable, CD-ROM and video content) to scheduled classes (live instruction in classroom settings or online) to group learning (online forums and chats).

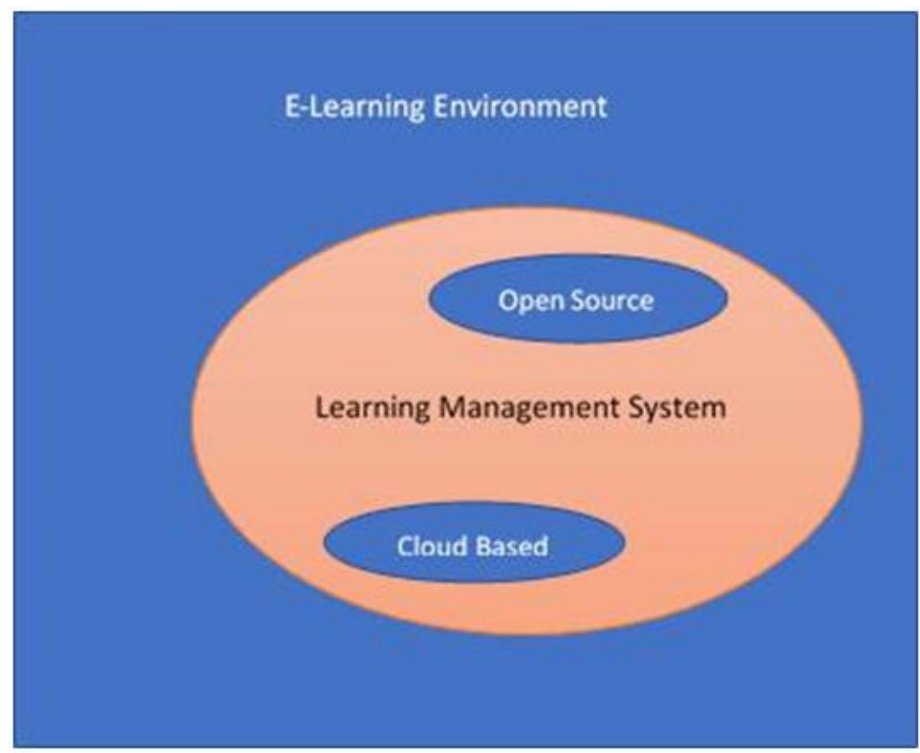

Fig. 1.LMS within e-learning environment.

According to Hall, optimally an LMS will consolidate mixed-media training initiatives, automate the selection and administration of courses, assemble and deliver learning content, measure learning effectiveness and integrate with other enterprise applications [10]. 
Thus, while evaluating an LMS the following criteria are important:

- High availability: The LMS platform must be robust and available.

- Scalability: Scalable to meet future growth.

- Usability: Supportive and easy to use.

- Interoperability: The LMS should support resources from different sources and satisfy different industry standards.

- Stability: Reliable infrastructure.

- Security: The platform should be secured.

Moreover, as the functionality of each system (LMS) such as communication tools, studentstudent interaction tools, student-instructor interaction tools, open source or cloud based differ widely it is important to keep in mind the requirement for individual institution while selecting an online learning management platform. Also, the strength and limitations of each platform, how to integrate this new innovation within the existing environment should be considered. Open source learning platform provide the code free, are online, flexible and each organization/enterprise can adept accordingly. Cloud-based platform also known as software as a service (SAAS) are hosted on the cloud and maintained by the vendors. The software can be accessed using a password, where by online learners and collaborator can use the system. The downside is that an internet connection is required to retrieve information and cannot be customized as compared to the flexibility of the open source platform.

\subsection{Review of Learning Management Systems (LMS)}

According to William Fenton, author and contributing editor for PC Mag, Australia IWhatever form online education may take, educators and administrators generally rely upon some kind of LMS to develop and assign course content, track student progress, and measure and report student outcomes." [11]. LMS software have evolved and matured as in the late 1900, Blackboard Learn was widely used followed by D2L Brightspace in the early 2000. Moreover, innovative technology, revolutionized LMSs with added functionality that cater for individual institution or e-learning requirements. According to G2 Crowd, LMS software are rated based on user review and market presence which is again based on product, scale focus and influence, as placed into four categories on the Grid R [12].

- Leaders include: Google Classroom, Blackboard Learn, Canvas Moodle, Schoology, Edmodo, Brightspace, and Litmos by SAP.

- High Performers are highly rated by their users, but have not yet achieved the Market Presence of the Leaders High Performers include: Frontline Professional Growth, Eds by, Talent LMS, Thought Industries, Showbie, Chamilo LMS, NEO, Kannu, and Path LMS.

- Contenders have significant market presence and resources, but have received below average user Satisfaction ratings or have not yet received a sufficient number of reviews to validate the solution. Contenders include: MindTap, Skyward, In nite Campus, and Engrade.

- Niche solutions do not have the Market Presence of the Leaders. They may have been rated positively on customer's satisfaction, but have not yet received enough reviews to validate them. Niche products include: Blackboard open LMS, Zoho Wiki, WizIQ, Sakai 11, Latitude Learning and Learn Dash.

Presented in Fig. 2 are the LMS on the grid based on customer satisfaction and market presence. Similarly, a comparison of the LMS form 2016-2017 based on market share for US and Canadian higher educational institution are depicted in Table. 1. From the table it can be seen that, Blackboard Learn and Moodle scored higher percentages for Fall 2017 by Institutions, Fall 2016 by Institutions and Fall 2017 by Enrollments as 28\%,31\%,37\% and 25\%.,5\%,12\% respectively. Moreover, Instructure Canvas and D2L Brightspace scored higher than Moodle for Fall 2017 by Enrollments as $27 \%$ and $15 \%$ [13]. Also, an updated LMS market share graphic for US and Canadian higher education highlighting the story of the market over time is shown in Fig. 3. In this graph, the width of each band represents the percentage of institutions using a particular LMS as its primary system. 

Vol. 3, No. 1, March 2019, pp. 13-21

In Table 1, the comparison clearly shows that Blackboard Learn and Moodle are mostly preferred followed by Canvas and D2LBrightspace.

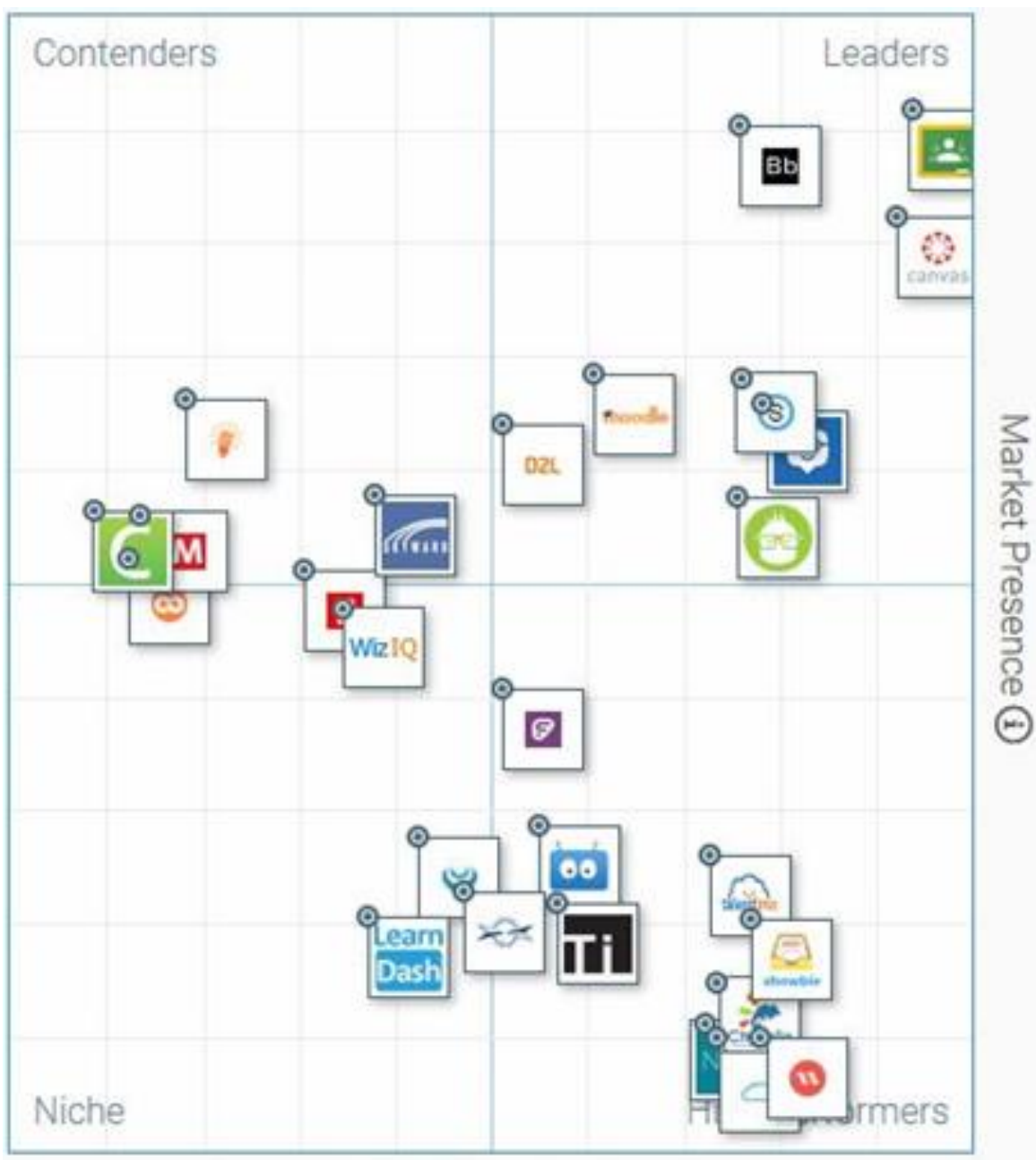

\section{Satisfaction (i)}

Fig. 2.LMS on the grid based on customer satisfaction and market presence [12].

\section{LEARNING MANAGEMENT SYSTEM}

\section{LEARNING PLATFORM}

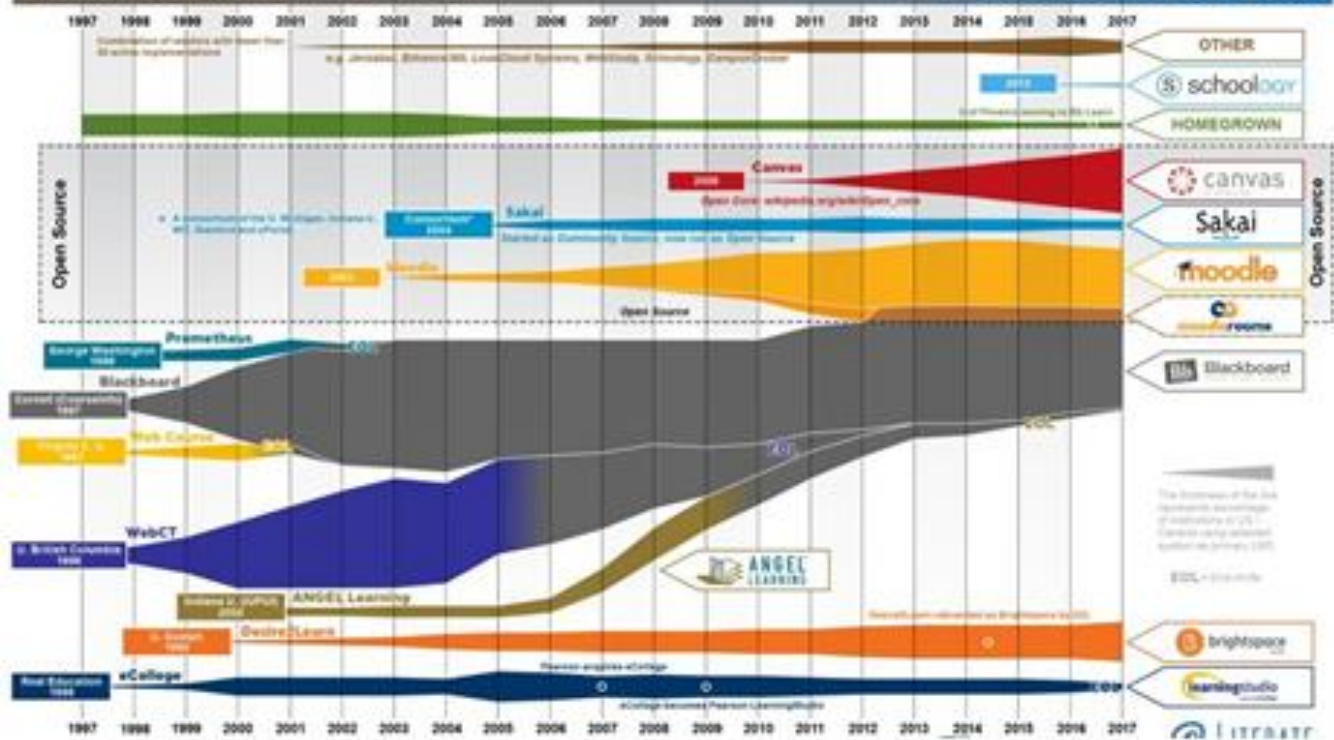

Fig. 3.LMS timeline (1997-2017). 
Table.1 Comparison Of LMS Share in US and Canadian Higher Educational Institution (2016-17) [13]

\begin{tabular}{cccc}
\hline LMS Solution & $\begin{array}{c}\text { Fall 2017 by } \\
\text { Institutions }\end{array}$ & $\begin{array}{c}\text { Fall 2016 by } \\
\text { Institutions }\end{array}$ & $\begin{array}{c}\text { Fall 2017 by } \\
\text { Enrollments }\end{array}$ \\
\hline Blackboard Learn & $28 \%$ & $31 \%$ & $37 \%$ \\
\hline Instructure Canvas & $21 \%$ & $17 \%$ & $27 \%$ \\
\hline D2LBrightspace & $13 \%$ & $11 \%$ & $15 \%$ \\
\hline Moodle & $25 \%$ & $25 \%$ & $12 \%$ \\
\hline Sakai & $3 \%$ & $3 \%$ & $3 \%$ \\
\hline Homegrown LMS & $2 \%$ & $2 \%$ & $3 \%$ \\
\hline Others & $4 \%$ & $6 \%$ & $1 \%$ \\
\hline BNED LoudCloud Learning & $0 \%$ & $0 \%$ & $1 \%$ \\
\hline Blackboard ANGEL & $1 \%$ & $1 \%$ & $1 \%$ \\
\hline Pearson LearningStudio & $2 \%$ & $4 \%$ & $0 \%$ \\
\hline Schoology LMS & $1 \%$ & $0 \%$ & $0 \%$
\end{tabular}

The best LMS for 2018 compiled by Fenton are Absorb, Moodle, Canvas, Schoology, Blackboard Learn, Brightspace, Edmodo, Qiuzlet and Google class-room, based on editor's rating, SCORM (technical standard for e-learning soft-ware), Bundled Course Content, Single Sign-On (SSO),E-Commerce, Developer API, Available LTI Support, and Native Web Hosting [11]. Another reviewer collated the best LMS based on popularity, which are Canvas, Blackboard Learn, Google Classroom, Moodle, TalentLMS, Schoology, Litmos, Edmodo, Brightspace [13].

\subsection{Comparison of the Best Learning Management System}

As LMS software provide a solution for the online learning management they are used extensively to empower instructors and learners with flexible teaching/learning methods, educational technologies, interaction mechanisms or learning resources, to provide an interactive learning environment to overcome the limitations of classroom and e-Learning [7]. Thus, this section presents a critical review of the popular LMS as identified by Fenton and Hill, based on their compatibility, usefulness, security, accessibility, scalability, stability/reliability and design [11], [13].

The learning management system Absorb is an industry based software, de-signed for employee training but is scalable. The software provides the learner accessible and intuitive experience along with a cost-effective and powerful administrative tool that integrates efficiently. The LMS is compatible, useful and secured. Similarly, Moodle with its modular plugins based design is an open source, secure, robust, and scalable integrated system to empower educators, administrators and learners to create learning environments.

Blackboard/Blackboard Learn on the other hand is a well-equipped K-12 learning management platform used by most educational institution including Australia. But the software is not user friendly, has interface and reliability issues.

Thus, Canvas is similar to Moodle in some aspect as this being open, usable, educational, but is a cloud-based technologies, that enables easy integration of the content, tools, and services that teacher's need and students want. Not surprisingly, it is a usable, customizable, adaptable, and reliable learning platform. Likewise, Schoology is an educational learning management system for $\mathrm{K}-12$, the platform is easy to integrate, secured with important information accessible at one point.

Therefore, Brightspace is an user-friendly LMS, that allow the instructor to have enormous control over the software. The downside is the limited features and functionality and not scalable. Moreover, Edmodo is a centralized classroom that connects teachers with students, colleague, and parents, also enabling them to share content, distribute quizzes, assignments. The online portal offers communication, collaboration, and coaching platform to K-12 schools and teachers.

Quizlet provides a simple learning environment for students to study using ashcards and games. The student can access information and collaborate effectively and study more efficiently. Along the line, the Google Classroom is an educational software that provides the educator to communicate with their students beyond classroom. Some of the features and design needs improvement for the software to be scalable and compatible. 
But, TalentLMS is a fully customized and comprehensible cloud based LMS suitable to train employees, customers and partners. It is flexible and can be integrated with SCROM authoring tools. The platform is simple for learning and management. Furthermore, Litmos is a cloud based learning environment de-signed to provide content based learning solution and management to meet employees training within an organization.

Novo-corti et.al applied e-learning and face-face using Moodle. The report shows that Moodle promotes the participation of students, increases their motivation and improves their competence and their performance in terms of qualifications [14]. Thus the Moodle learning management system is the more edacious and effective learning management system than the Blackboard learning management system [15]. As Moodle was easier to administer and allowed for better organization of their course materials so would consider using the platform in future.

\section{Moodle at UniSA}

The University of South Australia used Moodle as an LMS to embed their online teaching and learning framework, Learnonline that enables creation of a unique course site for each offering of a course. The word Moodle stands for Modular Object Oriented Dynamic Learning Environment that can be customized to support academic staff and students in their teaching and learning activities. The Moodle LMS platform is an open source software application that is comprehensive, scalable, secure and easily manageable. As many other universities, UniSA has customized it to create and power all our course websites.Students enrolled in a course will gain automatic access to the course web site which is retained for one year after the conclusion of the course. An example of a course web site within the UniSA Moodle environment is shown in Fig. 4.

Each lecturer can edit the course website template and customize it to his/her needs. Each course website includes teaching materials like, lecture notes, lecture video recordings, and other multimedia resources; then activities that students need to complete like, assessment tasks, formative quizzes, etc. Students are uploading assessment tasks online which are by default tested for plagiarism via TurnItIn and reports are readily available to lecturers when they assess the assignments. Marks are recorded in the system and the final marks and grades are generated by the system at the completion of the course.

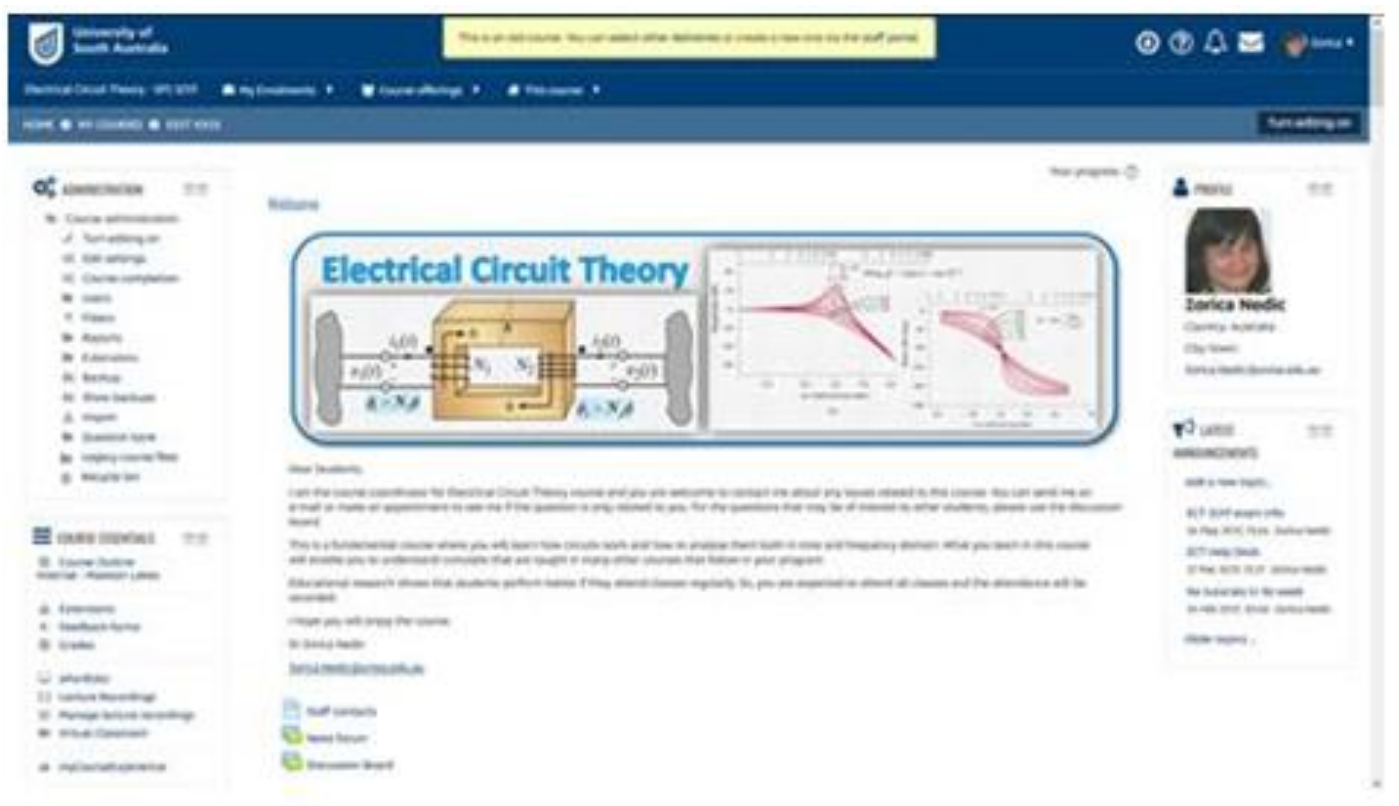

Fig. 4. A course website example.

This is very helpful for lecturers and reduces the risk of errors. Lecturers also have an option to upload marked assignments with marks and feedbacks for students on their work. For each assessment task students can view the grade distribution of the whole class so they can compare their own performance with the performance of the rest of the class which helps students evaluate their own performance. 
The UniSA Moodle application also provides a number of reports to lecturers so they can monitor student activities, behavior and performance. Fig.5 shows a course dashboard with some of the reports available to lecturers, like how many students accessed the course website, which resources were most assessed over the past week, etc.

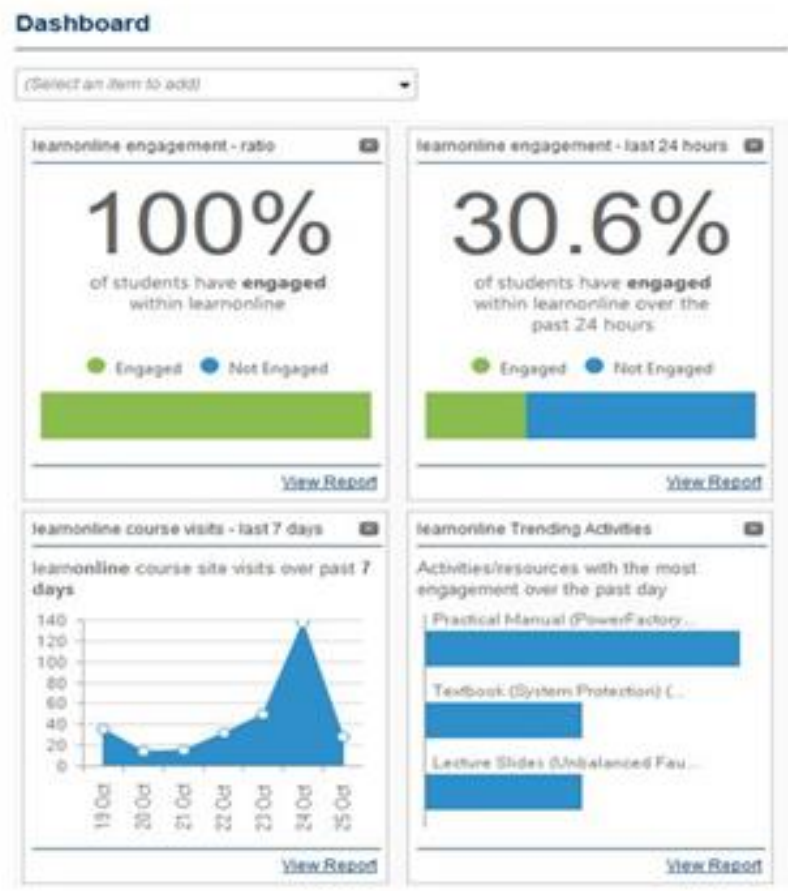

Fig. 5. Course dashboard showing various reports on student activities.

Details of reports can also be viewed for more comprehensive analysis of students' engagement as shown in Fig. 6. A lecturer can further see even more details down to which student did what (see link in top right-hand corner).

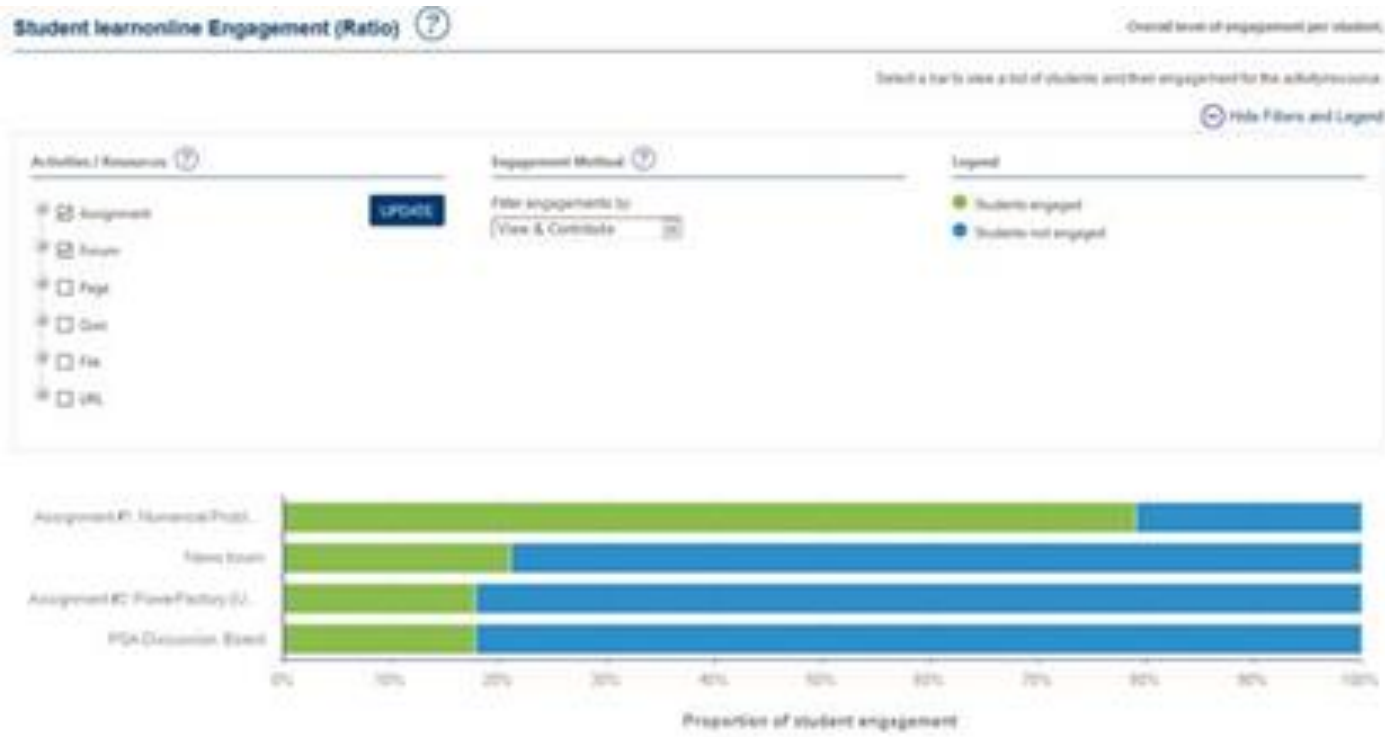

Fig. 6. Report with more details on student engagement.

In summary, the Moodle at UniSA is usefully customized and implemented in such a way to provide both students and staff with a rich online educational platform suitable for contemporary teaching and learning activities. 


\section{Online Remote Laboratory Netlab at UniSA}

NetLab is a remote laboratory developed at UniSA is one of the very rust remote laboratory developed in Australia. NetLab is an open access platform that enables students and any other user to remotely access real equipment at UniSA and to perform experiments from anywhere in the world and at any time as it is online 24/7. It is developed in Java software and is linked to websites of all courses that use NetLab in teaching. It is also very useful for lecturers as they can perform laboratory experiments in lecture theatres and thus teach students not only theory but also hands-on skills necessary for controlling experiments in a laboratory. This remote laboratory is suitable for experiments on basic passive electrical circuits and can be used in courses like introductory electrical engineering course, electrical circuit theory and signals and systems courses.

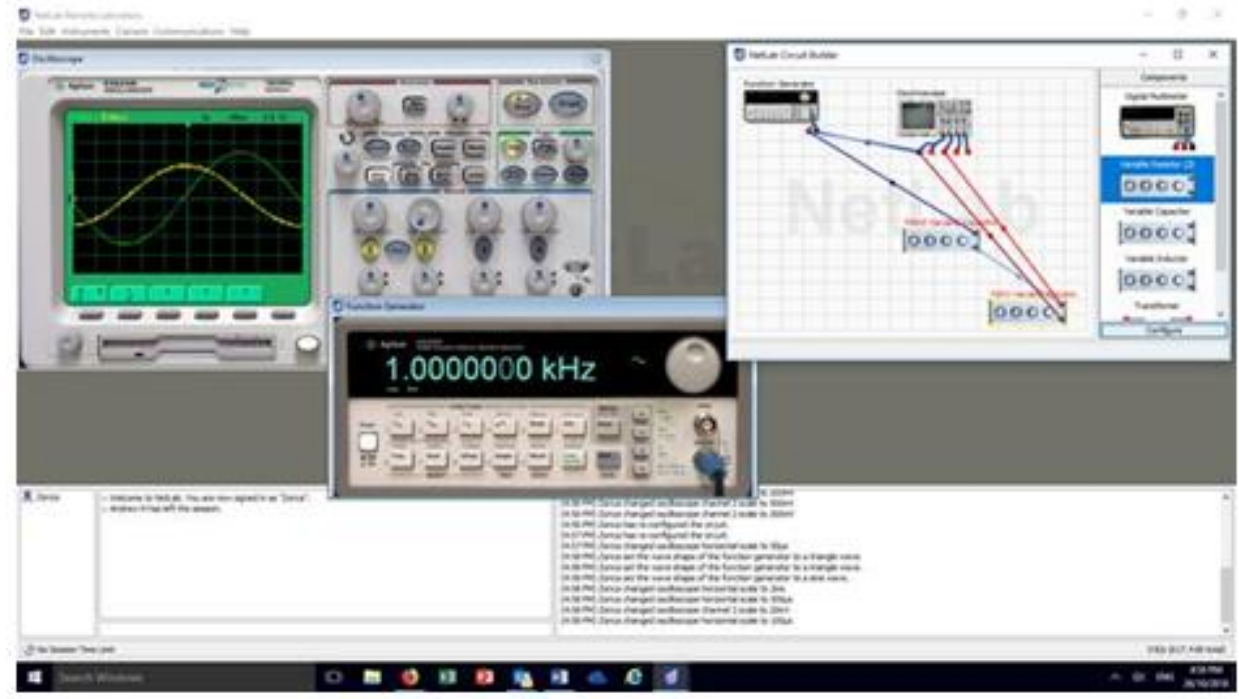

Fig. 7.NetLab graphical user interface.

NetLab graphical user interface is shown in Fig. 7. It includes basic electronic instruments; function generator, oscilloscope and digital multimeter and a range of passive components like resistors, capacitors and inductors. NetLab is open access and can be accessed at http://netlab2.unisa.edu.au/. Although NetLab was not developed within the Moodle, it is an online educational environment and an excellent example of additional resources used in online teaching.

\section{Conclusion}

Recent advances in technology and the Internet, has seen the concept of teaching and learning evolve significantly. Conventional face-to-face teaching is becoming a thing of the past as knowledge is everywhere and accessible from anywhere. Thus, a shift to e-learning is leveraging educational institute, companies, individuals and training organizations to embracing new technology and creating a shared online platform to facilitate learning, referred to as the Learning Management Systems (LMS). The literature review of the top ten LMS shows that Blackboard and Moodle are most widely used. Moreover, as the functionality of each system (LMS) such as communication tools, student-student interaction tools, student-instructor interaction tools, open source or cloud based differ widely it is important to keep in mind the requirement for individual institution while selecting an online learning management platform. UniSA has customized and implemented the Moodle in such a way that it provide both students and staff with a rich online educational platform. Furthermore, though the NetLab was not developed within the Moodle, it is still an online educational environment and an excellent example of additional resources used in online teaching. 


\section{References}

[1] P. Tóth, "Virtual learning approach in vocational initial teacher training," in Proceedings of the International Conference on Engineering Education, 2007.

[2] C. R. Graham, Blended Learning Systems: Definition, Current Trends, and Future Directions. In C. J. Bonk \& C. R. Graham (Ed.), The Handbook of Blended Learning: Global Perspectives, Local Designs, San Fransi. Pfeiffer Publishing, 2006.

[3] J. MacDonald, Blended learning and online tutoring: Planning learner support and activity design. Gower Publishing Ltd., 2008.

[4] M. V. López-Pérez, M. C. Pérez-López, and L. Rodríguez-Ariza, "Blended learning in higher education: Students' perceptions and their relation to outcomes," Comput. Educ., vol. 56, no. 3, pp. 818-826, 2011.

[5] A. Carr-Chellman, D. Dyer, and J. Breman, "Burrowing through the network wires: Does distance detract from collaborative authentic learning?," Int. J. E-Learning Distance Educ., vol. 15, no. 1, pp. 39$62,2000$.

[6] M. Gabriel, "Learning together: Exploring group interactions online," J. distance Educ., vol. 19, no. 1, pp. 54-72, 2004.

[7] H. J. So and T. A. Brush, "Student perceptions of collaborative learning, social presence and satisfaction in a blended learning environment: Relationships and critical factors," Comput. Educ., vol. 51, no. 1, pp. 318-336, 2008.

[8] T. Wilen-Daugenti, edu: Technology and learning environments in higher education. New York: Peter Lang, 2009.

[9] R. M. Gagne and L. J. Briggs, Principles of instructional design. Holt: Rinehart \& Winston, 1974.

[10] J. L. Hall, “Assessing Learning Management Systems,” Learning Delivery, 2002. [Online]. Available: https://www.chieflearningofficer.com/2002/12/11/assessing-learning-management-systems/. [Accessed: 01-Sep-2018].

[11]W. Fenton, “The Best (LMS) Learning Management Systems for 2018," Education, 2018. [Online]. Available: https://www.pcmag.com/roundup/336308/the-best-lms-learning-management-systems. [Accessed: 01-Sep-2018].

[12]G2 Crowd, "Best Learning Management System (LMS) Software," 2018. [Online]. Available: https://www.g2.com/categories/learning-management-system-lms. [Accessed: 01-Sep-2018].

[13]P. Hill, "State of Higher Ed LMS Market for US and Canada: Fall 2017 Edition," LMS \& Learning Platforms, 2017. [Online]. Available: https://mfeldstein.com/state-higher-ed-lms-market-us-canada-fall2017-edition/. [Accessed: 01-Sep-2018].

[14] I. Novo-Corti, L. Varela-Candamio, and M. Ramil-DíAz, "E-learning and face to face mixed methodology: Evaluating effectiveness of e-learning and perceived satisfaction for a microeconomic course using the Moodle platform," Comput. Human Behav., vol. 29, no. 2, pp. 410-415, 2013.

[15]M. Machado and E. Tao, "Blackboard vs. Moodle: Comparing user experience of learning management systems," in 2007 37th annual frontiers in education conference-global engineering: Knowledge without borders, opportunities without passports, 2007. 